\title{
EMISSIONS SCENARIOS: A FINAL RESPONSE ${ }^{1}$
}

\author{
Arnulf Grübler, Nebojsa Nakicenovic, Joe Alcamo, Ged Davis, \\ Joergen Fenhann, Bill Hare, Shunsuke Mori, Bill Pepper, Hugh Pitcher, \\ Keywan Riahi, Hans-Holger Rogner, Emilo Lebre La Rovere, \\ Alexei Sankovski, Michael Schlesinger, R.P. Shukla, Rob Swart, \\ Nadejda Victor and Tae Yong Jung
}

\section{ACKNOWLEDGEMENTS:}

We thank Vadim Chirkov and Erik Slentoe for their assistance in preparing this response.

\begin{abstract}
This note is a final response to the debate raised by Mr. Castles and Mr. Henderson (for brevity, we refer here to the two authors simply as $\mathrm{C} \& \mathrm{H}$ ) in this Journal (vol 14 , no $2 \& 3$, and no 4) on the issue of economic growth in developing countries in some of the emissions scenarios published in the IPCC Special Report on Emissions Scenarios (SRES) (Nakicenovic et al., 2000). We first outline areas of agreement and then the remaining areas of disagreement. Two important areas of agreement have emerged from the debate according to our view.

First, both parties agree that scenarios assuming a conditional convergence in income levels, i.e., a higher growth in per capita income in poorer countries when compared to countries with higher levels of affluence, are both "plausible and well attested in economic history" (C\&H, p. 424). Thus, the fundamental, structural characteristic of some of the SRES scenarios contested by C\&H are not challenged per se, but rather how fast such trends could unfold in the future.

Second, there is agreement on the value of considering purchasing power parities (PPP) in the international comparison of income levels and the need for further research to improve on the paucity of reliable PPP estimates for developing countries within the International Comparisons Project (ICP) (C\&H, p. 432). We appreciate that $\mathrm{C} \& \mathrm{H}$ have now acknowledged that PPPs were considered in developing the SRES scenarios and that they are reported in the data appendix of
\end{abstract}

\footnotetext{
${ }^{1}$ Views or opinions expressed herein are those of the authors and do not necessarily represent those of the Intergovernmental Panel on Climate Change or any other organization. Correspondence should be sent to Nebojsa Nakicenovic, IIASA, A-2361 Laxenburg, Austria (email: naki@iiasa.ac.at).

The following lead authors of the Special Report on Emissions Scenarios did not have time to review and contribute to this response written by Nakicenovic et al. (this issue). They wish to express their support for the general technical points made and affirm the overall soundness of the SRES: Ernst Worrell and Xiaoshi Xing.
} 
the report (C\&H, p. 422-423). Thus, it was not ignorance as suggested by $\mathrm{C} \& \mathrm{H}$ but rather sound empirical and methodological reasons that led the SRES team to use market exchange rates (MER) as the main metric in developing long-term emissions scenarios. This is in agreement with the underlying scenario literature. However, we do agree with $\mathrm{C} \& \mathrm{H}$ on the value of considering PPP as a complementary metric, and have indeed reported corresponding PPP scenarios in SRES. We disagree with C\&H that PPP ought to be used as the sole measure in developing long-term emissions scenarios.

This leads us to the remaining areas of disagreement.

(1) An important area of disagreement is that emissions do not depend on the metric used to measure economic activities. Evidently, historical emissions do not change as a function of whether historical development is measured in PPP or MER and both measures can be used interchangeably given appropriate model calibrations are deployed to assess the resulting emissions. More importantly, future emissions depend first of all on the physical characteristics of the energy system, land use and other human activities that need to be represented in models to calculate future emissions of greenhouse gases. These physical model representations are unaffected by the choice of PPP or MER for measuring economic growth. This fact explains why many of the emissions scenarios in the literature do not include economic development paths but rather determine emissions from human activities, such as energy and food services. We have addressed this argument extensively in the earlier issue of this Journal ( vol 14, no 2\&3).

(2) There also remains an important disagreement on the issue of using market exchange rates (MER) GDP in developing emission scenarios. $\mathrm{C} \& \mathrm{H}$ hold the extreme view that MER - a directly observable economic variable, as opposed to PPP, which is an elaborate statistical construct - should not be used at all in economic comparisons and in developing scenarios of GDP growth. We reiterate that there are good theoretical, methodological, and empirical reasons for using MER. Contrary to their claim of "unsound" practices, the SRES scenarios are consistent with the underlying literature, available methodologies, and existing practices of economic growth projections of leading international (e.g., the World Bank) and national institutions (e.g., the US DOE Energy Information Administration).

(3) A final area of disagreement is whether the $\mathrm{C} \& \mathrm{H}$ criticism is significant or a "red herring". C\&H (p. 428-429) claim that by lowering the economic growth rates for developing countries in the lowest SRES emission-scenarios, one should obtain even lower future emissions. Thus, they claim that the SRES scenarios have failed to represent the lower bound of uncertainty of future emission levels. Here C\&H display either a misunderstanding or misrepresentation of economic activity as the sole, independent driver of future emissions. Higher economic growth generally results in higher R\&D, more rapid capital turnover, more energy efficiency and higher preferences for pollution controls, all of which tend to reduce GHG emissions. Depending on how these are modeled, lower GDP growth may actually result in higher GHG emissions, and may not, as C\&H contend, significantly lower the SRES emissions in the absence of climate policies. We disagree that lower economic development would necessarily result in lower emissions. 
We conclude our response with some suggestions for improved clarity in the debate and the need to quantify differences in opinion through alternative scenarios published in the peer-reviewed literature.

\section{INTRODUCTION}

Previous issues of this Journal ( $\operatorname{vol} 14$, no $2 \& 3$, and no 4) have presented a debate publicly initiated by C\&H (Mr. Castles and Mr. Henderson) on the appropriate economic metric and numerical values for long-term economic growth scenarios within the context of long-term greenhouse gas (GHG) emissions scenarios as presented in the IPCC Special Report on Emissions Scenarios (SRES). The present note is a concluding rejoinder to the last article by $\mathrm{C} \& \mathrm{H}$ that appeared in vol 14 , no 4 , pp. 415-435 of this Journal in which $\mathrm{C} \& \mathrm{H}$ have restated their arguments at considerable length, in part responding to our earlier exchange (vol 14, no $2 \& 3$ ).

Our comments will be brief, as we do not believe that voluminous repetition lends any additional credence to the arguments we consider have already been dispelled in our previous exchanges with $\mathrm{C} \& \mathrm{H}$.

As a reminder to the readers of this Journal, the present debate centers around the issue of economic growth in developing countries as modeled in SRES. C\&H have accused the SRES authors and the IPCC as a whole of acting in a professionally "unsound" manner. According to their view, long-term economic growth must solely be described using purchasing power parities (PPP), rather than market exchange rates (MER), for comparing gross domestic products (GDP) of different world regions. C\&H also contend that the growth rates assumed in some of the SRES scenarios for developing countries are "absurdly" high, inconsistent with historical experience and the underlying scenario literature. We have argued that the SRES, in its use of MER, fully reflects the state-of-the art methodology for developing such long-term scenarios. Further, SRES did also use PPP for many of its scenarios as an alternative, complementary metric. Regardless of whether MER or PPP is used consistently in a comparison with the underlying scenario literature with the same metric (MER or PPP, respectively), the SRES scenarios - contrary to the claims by C\&H - do not appear at all extreme. Rather, they reflect a wide range of future possibilities that characterize our current understanding of the uncertainties of the drivers of future emissions patterns.

In the following sections we briefly outline our understanding of the areas of agreement that have emerged in the debate, and the important differences that remain. We conclude with some observations on the way $\mathrm{C} \& \mathrm{H}$ have conducted the debate thus far. We feel that $\mathrm{C} \& \mathrm{H}$ have quoted selectively from the literature and that much greater clarity, precision, and comprehensiveness is required in the presentation and criticism of SRES. A peer-reviewed evaluation of their criticisms could resolve some of these issues and help inform future emissions assessments. We also call for a more openminded discussion of the uncertainties associated with inevitably unknowable futures, minimizing any preconceived ideological or methodological biases. Finally, we emphasize the need for publication of alternative emissions scenarios in the peerreviewed literature, so these can be given appropriate consideration in future scientific assessments. 


\section{AREAS OF AGREEMENT}

An important area of agreement that emerged from the debate in our view is that $\mathrm{C} \& \mathrm{H}$ agree with the conceptual model of conditional convergence that underlies the SRES scenarios. We also agree that it is plausible that economic growth may proceed more rapidly in developing countries than in the already industrialized nations. $\mathrm{C} \& \mathrm{H}$ criticized the SRES for being overoptimistic on economic growth in developing countries. They now call scenarios in which per capita incomes in poorer countries grow faster than in high-income, mature economies, both "plausible and well attested in economic history" (C\&H, p. 424), a statement with which we also fully agree. We emphasize here the term conditional convergence, meaning a closing of the income gap (however measured) in relative terms only, as no SRES scenario assumes that present disparities in per capita incomes would eventually close in absolute terms. In fact, absolute per capita income differences continue to grow across all SRES scenarios, this occurs independently of the metric - either MER or PPP - used to express current income differences. ${ }^{2}$ Further, one of the four scenario families, the A2 group of scenarios, does not lead to convergence between the developed and developing countries in per capita PPP, the current PPP income difference ratio of about four to one being maintained throughout the 21 st century.

We accept that $\mathrm{C} \& \mathrm{H}$ consider some SRES scenarios to be unrealistic. This notwithstanding, it is important to emphasize that even for the most extreme scenarios with the highest rates of economic growth, there is no disagreement on the fundamental, structural characteristic of conditional convergence underlying the economic development patterns of the scenario. Rather, there is disagreement on what should be the appropriate rates of growth. The SRES scenarios were, rightly, designed to assess the relevant uncertainties in important driving forces of future GHG emissions, and economic development is indeed one of the most important ones. Disagreement is thus on model parameters rather than on the conceptual model underlying the contested SRES B1 scenario. It is particularly important to emphasize this in view of the claims of $\mathrm{C} \& \mathrm{H}$ that such a scenario renders the work of SRES methodologically "unsound".

It is also important to reiterate at this point that the purpose of any scenario exercise such as SRES (as opposed to a deterministic "forecast") is not to artificially compress future uncertainties through some subjective a priori constraints on the range of "whatif-then" conditions that can be explored in a scenario exercise, especially relying on criteria which a limited group deem "realistic". The mandate for the SRES team was to reflect the scientific uncertainty as represented by publications in the available scenario literature. It is in this context that the high growth rates in some of the SRES scenarios

\footnotetext{
${ }^{2}$ For instance, in the much contested SRES B1 scenario, which we agree with C\&H is very optimistic, average per capita incomes in developing countries would increase from \$2,280 (PPP) in 1990 to approach some $\$ 40,000$ (PPP) per capita by 2100 , about twice the current OECD average, but only about 60 percent of the OECD average of $\$ 65,000$ (PPP) per capita in 2100. In absolute terms, the gap between the average income in developing and OECD countries increases substantially, from \$14,000 (PPP) in 1990 to $\$ 24,900$ in 2100.

We also wish to add that the economic growth projections in MER of the B1 scenario were developed in close collaboration with the Dutch Economic Planning Bureau and their WorldScan model, i.e., drawing precisely the kind of expertise residing in national economic agencies C\&H have criticized the SRES for having insufficiently drawn upon.
} 
criticized by $\mathrm{C} \& \mathrm{H}$ fulfill an important role, well inside the bounds of the underlying literature review (cf. discussion below). All those users of the SRES scenarios, including those who disagree with a particular subset of the range of possibilities as outlined by the entire set of 40 scenarios, should consider the alternatives as outlined for instance in the A2 and B2 scenario families. The SRES was designed to provide insights on uncertainty from a range of plausible scenarios, and not to assign likelihood to any of the alternative futures described by the set of 40 scenarios.

For an exercise assessing important uncertainties of future GHG emissions, it would constitute a serious methodological flaw to exclude the possibility of rapid economic development in the current developing countries. Likewise it would also constitute a serious flaw in the analysis not to consider alternative scenario uncertainties of a rapid or slow demographic transition, as well as rapid or slow technology developments in either fossil fuel or renewable technologies. Censorship of which major scenario uncertainties should be considered in the assessment would indeed be both poor science and a poor guide to policy-makers who must consider potential trade-offs (or not) among stated socio-economic goals for all relevant contingencies of future developments. In the case of the SRES scenarios, the main assumptions and scenario outcomes are both consistent with the historical experience and the underlying literature. Indeed, $\mathrm{C} \& \mathrm{H}$ may have missed the main insight here - that SRES suggests that even rapid economic growth may be compatible with low-end GHG futures.

We now turn to the issue of economic metric, i.e., to the issue of MER versus PPP. We agree with $\mathrm{C} \& \mathrm{H}$ on the value of considering PPP as an alternative measure in cross-country comparisons of quantities such as income levels and energy intensity. This is amply documented in the publication record of many of the SRES authors. It is also evident in the SRES report that presents PPP results for all key SRES scenarios. We also agree with $\mathrm{C} \& \mathrm{H}$ on the importance of further research to increase the number of reliable PPP estimates for developing countries within the International Comparisons Project (ICP) (C\&H, p. 432). These are needed to address the data inadequacies that drove SRES decisions to prefer MER as the more reliable measure of developing scenarios of long-term economic development. There is further agreement on the importance of complementing traditional expenditure-based PPP estimates with estimates focusing on value-added PPP. Our agreement with C\&H also stems from our desire to explore further methodological pluralism in the field of developing long-term emission scenarios. However, this is also the point where our positions depart sharply.

\section{AREAS OF DISAGREEMENT}

This section is divided into three subsections.

\subsection{Driving forces of emissions}

As we have argued extensively in the earlier issue of this Journal (vol 14, no 2\&3), emissions do not depend on the metric used to measure economic activities. Evidently, historical emissions do not change as a function of whether historical development is measured in PPP or MER and both measures can be used interchangeably given appropriate model calibration to the resulting emissions variable. This in fact is 
reflected in integrated assessment models that report both metrics of GDP such as the IIASA integrated set of models used in SRES. More importantly, future emissions depend on physical characteristics of the energy system, land use and other human activities that need to be represented in models to calculate future emissions of greenhouse gases. These physical model representations like levels and structure of future diets or types of technologies used in electricity generation are unaffected by the choice of the calibrating parameter for economic growth. Evidently, there are additional economic variables that will affect consumer and producer choices as reflected for instance in energy prices. However, as we argue below there are sound empirical and methodological reasons to use MER exchange rates in describing prices of internationally traded commodities. Our continued disagreement with $\mathrm{C} \& \mathrm{H}$ in our view arises from the fact that $\mathrm{C} \& \mathrm{H}$ narrowly focus in their debate on the economic metric for GDP growth, ignoring the essential further analytical steps in the representation of physical systems that are needed to calculate greenhouse gas emissions. In other words, GDP is an important, but in itself insufficient explanatory variable for describing differences in emissions, past, present, or future. This fact explains why many of the emissions scenarios in the literature do not include economic development paths but rather determine emissions from human activities, such as energy and food services. We have addressed this argument extensively in the earlier issue of this Journal ( ool 14, no 2\&3).

\subsection{Reasons for using MER and PPP}

We appreciate that $\mathrm{C} \& \mathrm{H}$ now acknowledge that the SRES authors and reviewers explicitly considered the use of PPP in the SRES report and its underlying scenario modeling work. This fact was pointed out to $\mathrm{C} \& \mathrm{H}$ repeatedly, even prior to the first critique published in this Journal. Contrary to the allegation by C\&H that "flawed" methodology was used to develop the SRES scenarios and their contention that the omission of a primary use of PPP is the result of an ignorance among the SRES authors and reviewers, three of us (Grübler, Nakicenovic and Rogner) have developed jointly with other colleagues the first set of PPP-based long-term emissions scenarios in a joint study between IIASA and the World Energy Council (Nakicenovic et al. 1998) which was quoted by $\mathrm{C} \& \mathrm{H}$ as an example of how PPP can be used in such scenarios.

We are also surprised to see that $\mathrm{C} \& H$ continue to dismiss the PPP scenarios derived with the IIASA integrated model as mere "memorandum items" (p. 423) despite the fact that the PPP scenarios portray exactly the features for which they call. The SRES shows that the differences between the MER and PPP growth rates are largest for developing regions where the two exchange rates currently differ substantially, but are insignificant for regions in which the current differences are small (i.e., for the OECD region). ${ }^{3}$ In other words, assuming that conditional

\footnotetext{
${ }^{3}$ The fact that MER and PPP scenarios are identical for the OECD region simply arises from the fact that the differences between these two measures are very small and would not affect the results substantially. Hence, no alternative scenarios for the evolution of relative prices, e.g., of Japan versus the US over a period of 100 years were formulated. We certainly welcome any suggestions $\mathrm{C} \& \mathrm{H}$ have to offer to improve upon PPP scenarios for OECD countries, but as mentioned above the impact on aggregate scenario results will be minor.
} 
convergence holds, it implies much higher growth rates for MER than for PPP for developing countries, and this is reflected in the SRES scenarios. Contrary to $\mathrm{C} \& \mathrm{H}$ claims (p. 422) that the main difference between the growth rates between the two measures is simply due to different weights in regional averages one needs to consider the differences between MER and PPP exchange rates not only from a static perspective (as appropriate for cross-country comparisons at any given moment in time) but also from a dynamic perspective. The important additional factor to consider in long-term scenarios is the tendency for factor price equalization as economies develop and are progressively integrated into world trade for successively larger components of their GDP, which leads to declining differences between PPP and MER. This again is reflected in the scenarios reported in SRES as well as in the scenario studies that report both GDP metrics, most notably those of the World Energy Council.

It is surprising to see that $\mathrm{C} \& \mathrm{H}$ applaud the PPP scenarios of the World Energy Council as exemplary, while dismissing the PPP scenarios presented in the SRES report, as both sets of PPP scenarios were derived with exactly the same methodology and the same integrated model. $\mathrm{C} \& \mathrm{H}$ correctly point out the few studies available in the literature to date that have used PPP. Altogether $\mathrm{C} \& \mathrm{H}$ and we have been able to identify only nine scenarios (cf. Table 2 below) outside SRES that report economic growth in terms of PPP, either exclusively or as an alternative metric to MER. In contrast, eight out of the 40 SRES scenarios report both MER and PPP. It is thus particularly striking to see C\&H short-shrifting the SRES scenarios in comparison to those in the available scenario literature. One of the important mandates for any IPCC document is to reflect the current state of knowledge through a careful literature review. The SRES report reviews 416 scenarios in the literature. Of those, 166 scenarios report GDP for the year 2050, and 148 for the year 2100. In all of them except for the nine cases mentioned above - MER is used to describe GDP growth. Most recent results, including a study by Manne and Richels (2003), regarding the use of PPP and MER in measuring economic development in integrated assessment models, confirm our position that the choice of exchange rate will have only a small influence on the emissions and the resulting temperature in the year 2100 .

MER continues to be the most widely used metric in scenarios of future developments of the world economy, energy use, and emissions. The SRES scenarios therefore follow state-of-the-art, well established practices of international or national institutions, as exemplified for instance by the World Bank (2003) Global Economic Prospects, or the US Departments of Energy's Energy Information Administration (USDOE, 2003) International Energy Outlook, all published since SRES, and all using MER.

We therefore restate that the SRES scenarios constitute an important methodological improvement over much of the scenario literature in that GDP growth is described therein using PPP (using one of the six integrated models that participated in SRES) in addition to the traditional MER. In contrast to this methodological pluralism, C\&H have set out on a crusade to dislodge the use of MER, be it for developing economic growth projections, emissions scenarios, or national submissions to the UNFCCC. Their effort would be more productive if they would 
instead attempt to develop long-term scenarios that incorporate some of the characteristics they claim to be essential for a more "realistic" view of future economic development in the world.

We continue to state our case on the methodological soundness of the use of MER for developing long-term emissions scenarios. Our reasons are both empirical and theoretical. MER can be observed in market transactions for any currency used anywhere globally at any instant of time, whereas PPP is a set of varying, elaborate statistical constructs, estimated at (irregular) time intervals or for a shorter time period. Even given the most valuable estimation efforts as performed e.g., by the ICP, there are important uncertainties remaining and PPP time series estimates are generally available only for shorter periods of time. ${ }^{4}$ We believe that the complex statistical construct that PPP represents is a long way from being sufficiently reliable to serve as the sole basis of any analysis of income comparisons in a cross section analysis, much less serve as the sole basis of long term trend analysis. In fact the right strategy, given these assessments, is exactly what SRES pursued-using a MER based approach with parallel analysis using PPP to supplement the data. Given the SRES mandate to pursue the literature, the approach of only using PPP as suggested by C\&H would also have been both inconsistent with the underlying literature and at risk of being weak on methodological grounds, at least until the 2003-2005 work of ICP will be completed.

Even considering that with ongoing statistical work some of the uncertainty problems can be overcome in the future with more comprehensive and reliable PPP estimates, especially for developing countries that would not reduce the value of information contained in MER.

The problem at hand for emissions scenarios is not the postulation of GDP growth scenarios in some metric, whether MER or PPP, but rather to explore the implications that economic growth has for energy use, agricultural practices, the deployment of technologies, and the resulting emissions. The main characteristic of energy and technology (and to a smaller extent also food) is that these commodities are traded globally. Hence their availability at any instant of time for a national economy cannot be determined on the basis of PPP exchange rates but rather on the basis of MER. The issue of trade is also of central importance for GHG emissions scenarios when various climate policies are to be assessed as well. (Recall that the main motivation of the SRES scenarios was to serve as a basis for the subsequent analysis of climate change mitigation, adaptation and impacts within the framework of the IPCC assessments.) Again carbon trade prices will be determined at the international level and not on the basis of PPP exchange rates.

There are thus fundamental and methodologically sound reasons why long-term emission scenario models have to date almost exclusively relied on MER. Whereas some models (including the IIASA integrated models) include an internal module to translate between MER and PPP, MER continues to be indispensable. For instance, the amount of

\footnotetext{
${ }^{4}$ E.g., the 2001 World Bank Development indicators on a CD ROM (World Bank, 2001) include countrylevel GDP, MER from 1960 to 1999 and GDP, PPP estimates from 1975 to 1999, based on only 34 participating countries in 1975, 64 in 1985 (UN, 1992) and reaching a global representative level in 1993 with 118 participating countries (ICP, 2003).
} 
oil China can import (and that may become available for domestic consumption) depends on the prevailing level of crude oil prices at the international level. In turn, its costs to the Chinese economy are determined by the MER of the Chinese currency and not by the PPP exchange rate. The same can be said on the availability of jet aircraft for the transport sector or advanced energy technologies such as combined-cycle gas turbines. It is these among many other numerous relationships that need to be represented to model alternative scenarios that link economic growth to growth in energy use, changes in the technology stock of an economy and the resulting GHG emissions.

C\&H claim (p. 430) that it is "a mistake to give the model-based scenario approach such near-exclusive emphasis", but they offer no alternative. Evidently, given adequate PPP estimates it may be possible to formulate PPP GDP growth scenarios relying exclusively on this measure using a simple spreadsheet. But what about the subsequent steps in the analysis? As mentioned above, we challenge $\mathrm{C} \& \mathrm{H}$ to construct long-term emission scenarios that contain: (1) all the salient information needed for climate models on all species of GHGs arising from a multitude of human activities and from many different sectors, and (2) all the information needed for subsequent policy analysis such as energy (and carbon) prices and quantities.

This would also be the only way for them to demonstrate their alleged claim that the lowest SRES scenario in terms of cumulative carbon emissions (B1T-MESSAGE) does not represent a lower bound of emissions ${ }^{5}$ in the absence of climate policies. $\mathrm{C} \& \mathrm{H}$ have argued that by lowering the GDP growth rates of this (and similar) scenarios, emissions levels would be reduced, presumably proportionally, although it remains unclear what level of emission reductions $\mathrm{C} \& \mathrm{H}$ would expect in the case of a substantially lowered economic growth scenario for developing countries.

\subsection{Lowering economic growth}

We disagree with $\mathrm{C} \& \mathrm{H}$ that significantly lowering the economic growth rates of developing countries in the SRES B1T scenario would reduce emissions correspondingly. The B1T scenario explores the upper bounds of the diffusion of non-fossil energy technologies and results in the lowest cumulative GHG emissions of the SRES scenarios. We disagree on theoretical and numerical grounds with the simplistic scaling perspective that $\mathrm{C} \& \mathrm{H}$ advance, namely that lower GDP automatically leads to lower emissions.

There is wide agreement in both the theoretical and empirical literature of the economics of technological change that technological progress does not come as a free good (Grübler et al., 1999). The widespread diffusion of advanced, low- and zero-carbon technologies that make a low-emission path, as described by the SRES B1T scenario, feasible is in fact contingent on sustained high levels of R\&D and technology deployment in niche markets. Only under such conditions could the prices of these advanced technologies be lowered to a level that they would become cost-competitive with conventional fossil fuel based technologies even in absence of climate policies. It is

\footnotetext{
${ }^{5}$ In fact, even assuming such a scenario could be developed, it would not matter for the assessment of climate change uncertainties such as temperature change. The lower bound of future emissions is defined by climate policy scenarios, which were explicitly excluded from SRES, but analyzed subsequently in the IPCC Third Assessment Report (TAR).
} 
equally a well-attested theoretical and empirical fact that diffusion rates of new technologies are closely linked to market growth, i.e., the rate of capital turnover in an economy (e.g., Mansfield et al., 1977; Freeman, 1994). If growth is stagnant, few opportunities arise for the deployment of new technologies resulting in slower technology improvement rates compared to a case with rapid capital turnover. Similar statements also hold for energy end-use technologies (efficiency improvements). Higher macroeconomic productivity growth (GDP per capita growth) leads to higher rates of structural change in an economy and to higher potentials for deployment of more efficient capital vintages. As a result, improvements in energy intensity (energy use per unit of GDP) have been identified as being closely related to macroeconomic productivity growth (WEA, 2000). It is because of the non-linear interdependence among variables that simplistic scaling assumptions are both inconsistent with theory and counterfactual.

Growth in emissions is frequently described in the literature as being the sum of component growth rates in underlying driving forces along the so-called IPAT identity. After some initial disagreement, $\mathrm{C} \& \mathrm{H}$ (p. 428) have conceded to our viewpoint on stressing the importance of the interdependence between the IPAT variables, in other words on the linkages between productivity growth (GDP per capita), energy intensity (energy use per unit GDP), and emissions intensity of energy (e.g., carbon emissions per unit energy). Despite the apparent dismissal of formal modeling by $\mathrm{C} \& \mathrm{H}$, it is precisely these models that can help shed light on the complex interplay between the variables. We disagreed earlier with the $\mathrm{C} \& \mathrm{H}$ conjecture that significantly lower economic growth rates for developing countries would reduce emissions. In fact, lower economic growth might instead increase emissions compared to the base case. In the meantime, we have developed a new scenario to address this question, the results of which are summarized in Table 1 . The new scenario is called simply B2P and does not result in lower emissions than B2 that served as the base case for lowering economic development perspectives.

Taking the original SRES $B 2^{6}$ as a base case, we have assumed that economic growth rates in developing countries would be substantially lower (reaching income levels of $\$ 9,000$ per capita in PPP terms by 2100 instead of the original $\$ 18,000)$. Given this lower economic growth, we then used the integrated set of IIASA models to analyze the implications for energy use (impact on energy intensity) and the diffusion of advanced non-carbon technologies (carbon intensity). As can be seen from Table 1, the impacts are substantial and non-linear. Lower economic growth would lead to slower improvements in energy intensity (i.e., energy use in B2P is significantly above those values a linear "downscaling" of GDP growth would suggest). It also leads to a very slow diffusion of advanced technologies (practically no improvements in carbon intensities). The resulting impact on emissions is that they are substantially higher than in the original base-case scenario $(15.5 \mathrm{GtC}$ by 2100 compared to some $13.8 \mathrm{GtC}$ in the original B2 scenario and that with a world GDP that falls from 232 Trillion PPP\$ in the base case B2 scenario to 145 Trillion in the B2P scenario). Thus, the modeling results confirm our initial hypothesis that emissions

\footnotetext{
${ }^{6}$ We adopt the SRES-B2 scenario as a base case as it portrays an intermediary level of per capita GDP growth in developing countries among the 4 SRES scenario families.
} 
would tend to increase rather than decrease in the case of substantial slower economic growth rates in the developing countries. This is in perfect agreement with both theory and empirical observations. Thus, we continue to maintain that the lowest SRES scenarios indeed represent a reasonable lower bound of future emissions in the absence of climate policies. The same is the case with the highest of the SRES emissions scenarios. We would welcome others to either corroborate our results, or prove the contrary, ideally using an accepted, formal methodology that enables the rigorous analysis of all salient interdependencies characteristic of the system drivers of GHG emissions. However, we would be also interested in "back-of-the-envelope" calculations. Given that $\mathrm{C} \& \mathrm{H}$ and we agree on the importance of the interrelationships among the variables as described in an IPAT identity, the only way to benefit the debate in a constructive manner is to work the numbers through in a consistent fashion, refraining from simplistic, erroneous "pro-rata" scaling techniques.

Table 1. Components of the IPAT identity and their growth rates

\begin{tabular}{|c|c|c|c|c|c|c|c|c|c|}
\hline \multicolumn{10}{|c|}{ Components of The IPAT Identity and Their Growth Rates } \\
\hline & \multicolumn{3}{|c|}{$\begin{array}{c}\text { Base Year } \\
1990\end{array}$} & \multicolumn{3}{|c|}{$\begin{array}{l}\text { Scenario MESSAGE B2 } \\
2100\end{array}$} & \multicolumn{3}{|c|}{$\begin{array}{c}\text { Scenario B2P } \\
2100 \\
\end{array}$} \\
\hline & IND & DEV & WORLD & IND & DEV & WORLD & IND & DEV & WORLD \\
\hline \multicolumn{10}{|c|}{ Components of the IPAT identity } \\
\hline Population, million & 1272 & 3990 & 5262 & 1307 & 9107 & 10414 & 1307 & 9107 & 10414 \\
\hline GDP $_{\text {MER }} /$ capita, US\$90 & 13758 & 852 & 3972 & 54399 & 17997 & 22556 & 54399 & 7136 & 13063 \\
\hline GDPPpp $_{\text {papita, }} \$ 90$ & 13064 & 2288 & 4893 & 50956 & 18151 & 22258 & 50922 & 8896 & 14170 \\
\hline $\mathrm{PE} / \mathrm{GDP}_{\mathrm{M} \in \mathrm{R},} \mathrm{MJ} / \mathrm{US} \$ 90$ & 13.1 & 36.2 & 16.8 & 5.6 & 5.8 & 5.8 & 5.0 & 11.3 & 8.0 \\
\hline $\mathrm{PE} / \mathrm{GDP}_{\mathrm{PPP}} \mathrm{MJ} / \$ 90$ & 13.8 & 13.5 & 13.7 & 6.0 & 5.8 & 5.9 & 5.3 & 9.1 & 7.4 \\
\hline $\mathrm{CO}_{2} / \mathrm{PE}-\mathrm{kgC} / \mathrm{MJ}$ & 18.1 & 15.2 & 17.0 & 10.7 & 9.9 & 10.2 & 13.3 & 14.7 & 14.3 \\
\hline $\mathrm{CO}_{2}(\mathrm{GtC})$ & 4.1 & 1.9 & 6.0 & 4.3 & 9.5 & 13.8 & 4.7 & 10.8 & 15.5 \\
\hline \multicolumn{10}{|c|}{ Annual average growth rates of the IPAT components } \\
\hline Population & & & & 0.02 & 0.75 & 0.62 & 0.02 & 0.75 & 0.62 \\
\hline $\mathrm{GDP}_{\mathrm{MER}} /$ capita & & & & 1.25 & 2.77 & 1.58 & 1.25 & 1.93 & 1.08 \\
\hline GDPpPp/capita & & & & 1.23 & 1.89 & 1.38 & 1.24 & 1.23 & 0.97 \\
\hline $\mathrm{PE} / \mathrm{GDP}_{\mathrm{MER}}$ & & & & -0.77 & -1.66 & -0.97 & -0.88 & $-1,06$ & -0.68 \\
\hline $\mathrm{PE} / \mathrm{GDP}_{\mathrm{PPP}}$ & & & & -0.75 & -0.77 & -0.77 & -0.86 & -0.36 & -0.56 \\
\hline $\mathrm{CO}_{2} / \mathrm{PE}$ & & & & -0.47 & -0.39 & -0.47 & -0.28 & -0.03 & -0.16 \\
\hline $\mathrm{CO}_{2}$ & & & & 0.03 & 1.48 & 0.76 & 0.12 & 1.60 & 0.86 \\
\hline \multicolumn{10}{|c|}{$\begin{array}{l}\text { IND- industrialized countries; DEV-developing countries; } \\
\text { GDP-gross domestic product; MER - market exdange rate; } P \text { PP-purchasing power parities: } P E \text {-primary energy }\end{array}$} \\
\hline $\begin{array}{l}\text { Notes: } \\
\text { Base yearvalues taken form } \\
\text { As the IPCC B } 2 \text { scenario ar }\end{array}$ & & $r t$ & -1 & 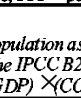 & mptions & & & & \\
\hline
\end{tabular}

\subsection{Economic growth rates}

We maintain that the SRES scenarios reflect well our current understanding of the uncertainties involved in future GHG emissions, including the issue of economic growth. When the comparison is made at the level of the appropriate and comparable metric (PPP or MER) the SRES scenarios compare well with the literature. ${ }^{7}$ This is

\footnotetext{
${ }^{7}$ The A1B-AIM scenario portrays higher growth rates in the first decades of the next century, but lower ones thereafter. When considered over the entire time period and in terms of resulting per capita income levels by 2100 , this scenario also lies within the range of comparable high growth scenarios available in the literature as explained in our previous response to $\mathrm{C} \& \mathrm{H}$.
} 
amply illustrated in Table 2. It shows that regardless of whether MER or PPP is used in a comparison with the underlying scenario literature with the same metric (MER or PPP, respectively), the SRES scenarios - contrary to the claims by $\mathrm{C} \& \mathrm{H}-$ do not appear at all extreme, especially when considering PPP, the preferred metric by $\mathrm{C} \& \mathrm{H}$. Rather, the scenarios reflect a wide range of future possibilities that characterize our current understanding of the range of future economic growth in emission scenarios.

Table 2. Economic growth in developing countries

\begin{tabular}{|c|c|c|c|c|c|c|c|c|c|}
\hline \multicolumn{10}{|c|}{ Economic Growth in Developing Countries } \\
\hline $\begin{array}{c}\text { Scenario } \\
\text { Source }\end{array}$ & Scenario & \multicolumn{2}{|c|}{\begin{tabular}{|c|}
2030 \\
as a multiple of \\
2000 \\
GDP $_{\text {MER }}$ \\
per cap \\
\end{tabular}} & \multicolumn{2}{|c|}{\begin{tabular}{|} 
Average \\
annual growth \\
rates \\
GDPMER \\
per cap \\
\end{tabular}} & \multicolumn{2}{|c|}{\begin{tabular}{|c|}
2030 \\
as a multiple of \\
2000 \\
GDP $_{\mathrm{PPP}}$ \\
per cap \\
\end{tabular}} & \multicolumn{2}{|c|}{$\begin{array}{c}\text { Average } \\
\text { annual growth } \\
\text { rates } \\
\text { GDP } \\
\text { Per cap } \\
\end{array}$} \\
\hline SRES & A1B-AIM & 6.03 & 8.46 & 6.17 & 7,38 & & & & \\
\hline SRES & A2-ASF & 2.12 & 3.34 & 2.53 & 4,11 & & & & \\
\hline SRES & B1-IMAGE & 3.94 & 5.52 & 4.68 & 5,86 & & & & \\
\hline SRES & B2-MESSAGE & 3.32 & 4.85 & 4.08 & 5.41 & 2.04 & 2.99 & 2.41 & 3.72 \\
\hline SRES & A1B-MESSAGE & 6.07 & 8.51 & 6.19 & 7,40 & 3.08 & 4.31 & 3.82 & 4.99 \\
\hline SRES & A2-MESSAGE & 2.12 & 3.34 & 2.53 & 4.11 & 1.76 & 2.78 & 1.90 & 3.46 \\
\hline SRES & B1-MESSAGE & 4,26 & 5.98 & 4.95 & 6.14 & 2,39 & 3.35 & 2,95 & 4.11 \\
\hline IIIASA/WEC & Case A & 2.45 & 3.68 & 3.03 & 4,44 & 1.77 & 2.66 & 1.93 & 3.32 \\
\hline IIIASA/WEC & Case B & 1.84 & 2.77 & 2.06 & 3.46 & 1.48 & 2.22 & 1.32 & 2.70 \\
\hline IIIASA/WEC & Case C & 2.16 & 3.24 & 2.60 & 4.00 & 1.64 & 2,47 & 1.67 & 3.06 \\
\hline POLES & Reference & & & & & 2.34 & 3.52 & 2.88 & 4.28 \\
\hline IEA & Reference & & & & & 2,29 & 3.34 & 2.80 & 4.10 \\
\hline WETO & (POLES model) & & & & & 2.42 & 3.44 & 2.99 & 4.20 \\
\hline WEC(1993) & A & & & & & & & 3.9 & \\
\hline WEC(1993) & $\mathrm{B}$ (reference) \& C & & & & & & & 2.9 & 4.6 \\
\hline DOE-EIA & Reference & & & 3.2 & 4,5 & & & & \\
\hline DOE-EIA & High growth & & & 4.2 & 5,5 & & & & \\
\hline DOE-EIA & Low Growth & & & 1.8 & 3.2 & & & & \\
\hline World Bank & $003)$ & & & 3.5 & 4.7 & & & & \\
\hline
\end{tabular}

Note: The growth rates for the WEC93(1990-2020), DOE-EIA(2000-2025) and World Bank(2003-2015) scenarios are based on time periods different than 2000-2030. Scenarios calibruted in both MER and PPP

Sources: SRES (IPCC, 2000); IIASA/WEC (Nakicenovic et al, 1998); POLES (Criqui, P. and Kouvaritakis, $\left.N_{1}, 2000\right) ;$ IEA (2002); WETO (Eurcpean Commission ${ }_{1}$ 2003); DOE-EIA (USDOE, 2003); World Bank (2003).

$\mathrm{C} \& \mathrm{H}$ have in their critique used selective quotation in making their case. They have excluded scenarios from the literature with high rates of economic growth and have instead compared (high) MER growth rates in SRES scenarios with (low) PPP growth rates from the literature. Such comparison of "apples with oranges", i.e., MER and PPP is inappropriate and misleading. This is perhaps best illustrated by Table 1 ( $\mathrm{p}$. 426) of their previous contribution to this Journal. In their comparison of the SRES scenarios with the literature they first selected 5 high growth cases from the set of 40 SRES scenarios, but only 2 of the lower growth cases. In fact, in terms of economic 
growth there are only four major scenarios, referred to as scenario families in the SRES report, so C\&H choice of scenarios is skewed. They omitted in their comparison with the literature precisely those PPP scenarios of the World Energy Council 1993 study they applaud earlier in their very paper. In conclusion, $\mathrm{C} \& \mathrm{H}$ have been seeding confusion by inappropriately comparing MER and PPP growth rates reported in different literature sources, as illustrated by both of their contributions to this Journal. Table 2 corrects the comparison of SRES with other scenarios in the literature by showing separately PPP and MER growth rates following the original C\&H format.

Further, C\&H have misinformed readers by suggesting that in SRES per capita incomes of developing countries would surpass those of the USA, whereas in reality this is not the case in any SRES scenario. They have made these claims by attributing to SRES unpublished and experimental attempts to downscale economic growth from the 4 world regions of SRES to national levels. These unpublished attempts were never agreed to by the SRES authors and were made well after the publication of SRES. The SRES report contains information only at the level of 4 world regions. It is also a well-established practice in science not to quote from unpublished work in progress by others without seeking permission from the authors concerned. Even though this downscaling exercise was neither a part of the SRES process nor is it in any way connected to the SRES report as published, we wish to express our concern here on the ridicule insinuated by $\mathrm{C} \& \mathrm{H}$, both in academic journals and in the popular press, of unpublished work in progress, out of context and without the consent of the authors concerned.

\section{CONCLUSION}

We maintain that the SRES scenarios reflect well our current understanding of the uncertainties involved in future GHG emissions, including the issue of economic growth. When the comparison is made at the level of the appropriate and comparable metric (PPP or MER) the SRES scenarios compare well with the literature.

We express our hope, however, that despite disagreement on numbers and economic metrics in long-term scenarios, $\mathrm{C} \& \mathrm{H}$ can join us in our plea for improved clarity and precision and careful documentation of numbers, whether they refer to MER or PPP. If this can be achieved, this debate might have finally resulted in something useful as well.

We also call upon for greater efforts in clarifying differences in emissions perspectives not only by qualitative critique but also through scenario quantifications. We have taken note of the disagreement of C\&H with some of the SRES scenarios but continue to miss specific suggestions for improvement.

Finally, we feel that in order to improve upon future work in this domain there is an urgent need to rely more on the peer-review process and literature. We are confident that a dialogue in rigorously peer-reviewed journals might help to eliminate much of the spurious controversy to date and identify areas where further improvement of methods and scenarios is required. A peer-reviewed evaluation of their criticisms could resolve some of these issues and help inform future work in this area. Publication of alternative emissions scenarios in the peer-reviewed literature are also a necessary precondition in order that these can be given appropriate consideration in future scientific assessments. 


\section{REFERENCES}

Castles, I. and Henderson, D., (2003). The IPCC Emission Scenarios: An Economic-Statistical Critique. Energy and Environment, Vol. 14, No. 2\&3, pp. 159-185.

Castles, I. and Henderson, D., (2003). Economics, Emissions Scenarios and the Work of the IPCC. Energy and Environment, Vol. 14, No. 4, pp. 415-435.

Criqui, P. and Kouvaritakis, N., (2000). World energy projections to 2030. International Journal of Global Energy Issues, Vol. 14, No. 1-4, pp. 116-136.

European Commission, (2003). World energy, technology and climate policy outlook (WETO). European Communities, Luxemburg.

Freeman, C., (1994). The ecomomics of technical change. Cambridge Journal of Economics, Vol. 18, pp. 463-514.

Grübler, A., Nakicenovic, N. and Victor, D.G., (1999), Dynamics of energy technologies and global change, Energy Policy, Vol. 27, pp. 247-280.

International Comparison Program (ICP), (2003). About the International Comparison Program. http://www.worldbank.org/data/icp/abouticp.htm

International Energy Agency (IEA), (2002). World Energy Outlook 2002. OECD/IEA, Paris.

Manne, A. S. and Richels, G., (2003). Market Exchange Rates or Purchasing Power Parity: Does the Choice Make a Difference to the Climate Debate? Working Paper 03-11. Sep 2003. AEI-Brookings Joint Center for Regulatory Studies.

http://aei-brookings.org/admin/pdffiles/phpqD.pdf

Mansfield, E. et al., (1977). The Production and Application of New Industrial Technology. W.W. Norton \& Company, Inc., New York, NY.

Nakicenovic, N. et al., (2003). IPCC SRES Revisited: A Response. Energy and Environment, Vol. 14, No. 2\&3, pp. 187-214.

Nakicenovic, N., Alcamo, J., Davis, G., de Vries, B., Fenhann, J., Gaffin, S., Gregory, K., Grübler, A. et al., (2000). Special Report on Emissions Scenarios (SRES). Intergovernmental Panel on Climate Change (IPCC), Cambridge University Press, Cambridge.

Nakicenovic, N., Grübler, A., and McDonald, A. (eds), (1998). Global Energy Perspectives. Cambridge University Press, Cambridge.

United Nations (UN), (1992). Handbook of the International Comparison Programme. UN, New York, NY.

US Department of Energy (USDOE), (2003): International Energy Outlook 2003. DOE/EIA. http://www.eia.doe.gov/emeu/international/forecast.html\#Mid-Term

World Energy Assessment (WEA), (2000). Energy and the challenge of sustainability. UNDP, New York, NY.

World Energy Council (WEC), (1993). Energy for Tomorrow's World. Kogan Page, St.Martin's Press, New York, NY.

World Bank, (2001). World Bank Development Indicators - 2001. World Bank, CD-ROM.

World Bank, (2003). Global Economic Prospects and the Developing Countries 2003. http://www.worldbank.org/prospects/gep2003/full.htm. 